\title{
Marketers are Consumers Too: Integrating Consumer-Self in Potential Value Creation
}

\author{
Michal J Carrington \\ University of Melbourne \\ Benjamin A Neville \\ University of Melbourne
}

\section{Structured Abstract:}

\section{Purpose}

This article explores the extent to which a marketer's own priorities as a consumer infiltrate workplace decisionmaking, and how this contamination influences the creation of potential value for the end consumer. The 'black box' of the organization is opened to investigate potential value creation at an individual/manager level of analysis.

\section{Design}

We gathered in-depth qualitative data from amongst 25 marketing managers and directors in the UK, Australia and the US. We theorised this data through boundary theory to develop an integrated producer-as-consumer potential value creation model.

\section{Findings and Research Implications}

The study reveals the dynamic interplay in marketing/production decision making between the individual's consumer-self, manager-self, and the external interface with the organisation. Additionally, the producer-asconsumer potential value creation model illuminates the complex role of the firm and its individual managers in the creation of potential value, and identifies contingencies that result in a spectrum of possible potential value creation outcomes. These contributions are positioned within the marketing value creation and co-creation literatures.

\section{Practical and Social Implications}

Marketing organisations/managers may find this research useful when considering the benefits and drawbacks of integrating managers' consumer-self insights into workplace decision making and the creation of potential value for the end consumer.

\section{Originality}

This article moves value creation/co-creation theory forward by revealing the dynamic potential value creation process and presenting a fluid representation of producers-as-consumers, at individual manager-level. This article is of interest to academic and marketing practitioner audiences.

\section{Keywords:}

Value creation, value co-creation, producers-as-consumers, boundary theory, marketing managers. 


\section{Marketers are Consumers Too: Integrating Consumer-Self in}

\section{Potential Value Creation}

'It's not about pop culture and it's not about fooling people, and it's not about convincing people that they want something they don't want. We figure out what we want. And I think we're pretty good at having the right discipline to think through whether a lot of people are going to want it too. That's what we get paid to do. So you can't go out and ask people, you know, what's the next big thing? There's a great quote by Henry Ford, right? He said, 'If I'd asked my customers what they wanted, they would have told me 'A faster horse'." (Steve Jobs, Interview, Morris 2008)

"I like to think that it's entirely consistent. I don't have to put a business hat on saying, 'Okay I'm coming to work now so that is what I have to believe today, and now I'm going home so I can take that hat off'; I think one of the benefits of not having to take a hat on and off is that you're in touch with your own thoughts and needs and desires and typically if I'm thinking it, then a lot of other people are thinking it as well." (Informant Keith, Interview)

Our study participant Keith and former Apple CEO Steve Jobs illustrate the convergence of priorities and values across two of their life domains - as a consumer and as a manager in the workplace. As Steve Jobs explains it, Apple's value creation process is not driven by traditional market research or by taking a customer orientation ${ }^{1}$ in the first instance, but by bringing their individual consumer-self to the fore in marketing decisions: "We figure out what we want". This merging of belief systems between an individual's consumer life and workplace decision-making raises an interesting question: to what extent do a marketer's priorities as a consumer infiltrate workplace decision-making and how does this transfusion between domains implicate value creation for the end consumer? This line of enquiry holds significant implications for marketing practice and theory.

The value co-creation and service-dominant logic (S-DL) literatures call for researchers to recognise that by the very nature of markets and consumption, consumers are

\footnotetext{
${ }^{1}$ In contrast to notions of consumer orientation where marketing managers 'walk in the shoes of the consumer', we present a perspective that recognises the marketing manager is also a consumer.
} 
often also producers (Prahalad and Ramaswarmy, 2004b; Vargo and Lusch, 2004; Cova, Dalli, and Zwick, 2011; Grönroos and Voima, 2013). In response, Ritzer, Dean and Jurgenson (2012) advance the concept of the prosumer: a consumer "who is both producer and consumer" ( $\mathrm{p}$ 379). Despite marketing scholarship moving to a more dynamic notion of consumers as producers of resources and creators of value, however, the treatment of firms within the value creation literature remains constrained to the static role of the 'producer' (e.g. Arvidsson, 2011). In this study, we problematise this view of the firm as a dichotomous entity juxtaposed against the consumer. We invert notions of 'consumer-as-producer' to consider that producers/managers are also consumers in their non-work life, and that the collision of these realms has implications for potential value creation. In this scenario, like Steve Jobs and Keith, managers embed their consumer-self ideals into marketing decisions and the end consumer offering with consequent implications for the potential value created.

In addition, this entrenched notion of a firm-consumer dyad limits perspectives of 'the firm' to a singular entity researched only at the organisational level. These perspectives fail to recognise that firms comprise a collection of individuals who have personal, consumer lives outside their workplace. In contrast, conceptual and empirical treatment of 'the consumer' in the value creation literature has focused at both the individual (e.g. Echeverri and Skålén, 2011) and collective/community levels (e.g. Schau et al., 2009). Thus, we suggest that the 'black box' of the organisation be opened to recognise that the 'producer' is comprised of individuals who also consume, and whose personal consumption experiences are likely to be significant in the production process. This potent agenda explores the dual lives of managers as consumers and the influence of this duality on the creation of potential value.

We address these limitations through an in-depth qualitative study involving 25 marketing managers and directors across the US, Australia, and the UK, who work within a range of branding, manufacturing and retail organisations, from small local operations to 
large-scale multinationals. The study is situated within the context of 'ethical' production and consumption, which is highly subjective and contentious, especially in the marketing and business realms (Porter and Kramer, 2011). This 'ethical' context therefore provides an ideal scenario to investigate the conscious transfusion of highly salient personal beliefs and ethical concerns - such as issues of child labour and environmental impact - into managerial decision making.

Our study makes two key contributions to marketing research and practice. First, we empirically extend the conception of individuals as central to value creation/co-creation (Prahalad and Ramaswarmy, 2004) and contrast notions of consumers-as-producers (e.g. Ritzer et al., 2012; Schau et al., 2009) by revealing that individual marketing managers integrate salient elements of their own consumption priorities into workplace decision making. While Grönroos and Voima (2013) conceive that producers/firms create potential value, consumers create actual value-in-use, and that value co-creation only occurs in firmconsumer interactions; we empirically integrate these three value creation scenarios by considering marketing managers as both producers and consumers. Our study illustrates that in this scenario of producer-as-consumer, the extent to which the consumer-self is integrated into production decisions as potential value creation is contingent upon the interplay between the individual's consumer-self, their internalised manager-self, and the external interface with the organisation. In addition, the integration of managerial and consumer-self can be bidirectional, where marketing managers also take priorities and ideals learnt in the workplace into out-of-work consumption decisions and practices.

We find that marketing managers are active agents, however, in this contingent value creation dynamic. In some scenarios, marketing managers manipulate and negotiate the managerial practices within strategic and political workplace arenas to embed their own salient consumption values into marketing/production decisions. In other situations, 
marketing managers withdraw their consumer-self from the workplace to manage the personal tension arising from conflict between work and consumer priorities. In extreme situations, marketing managers are forced to leave the firm when this conflict is unmanageable. We frame these responses to conflicting work and consumer priorities on a continuum of boundary work tactics with efforts to integrate the consumer-self into the creation of potential value at one end, and to withdraw their consumer-self from the workplace at the other end.

Second, we draw on boundary theory (Nippert-Eng, 1996; Kreiner, Hollensbe, and Sheep, 2009) previously developed within sociology and the organisation/management fields, to extend our findings and theorise an integrated producer-as-consumer potential value creation model. This model provides a new lens through which to understand the complex role of the firm and its managers in the creation of potential value. The integrated model presents an overarching process of potential value creation (Grönroos and Voima, 2013) at an individual manager level, and identifies contingencies that result in a spectrum of possible potential value creation outcomes.

We position these contributions within the marketing value creation, co-creation, and Service Logic (SL) literature streams, directly responding to Vargo et al.'s (2008) and Grönroos and Ravald's (2011) calls to investigate the mechanisms underpinning the facilitation, co-creation, and creation of value. Value creation is the pivotal concern for the marketing function (Grönroos and Ravald, 2011; AMA 2008), and the loci of value creation are in the interactions between the consumer and the market offering. Further, marketing managers determine the elements of potential value embedded in these market offerings through their daily workplace decision making, such as determining a brand's positioning in the market (e.g. luxury vs. affordable), the packaging cues, and the pricing structure of the brand. Thus, consumer experiences of value-in-use are contingent on the decisions of 
marketing managers. We argue that investigating the role of marketing managers' consumerself in the co-production of potential value embedded in the market offering presents substantial marketing insight to enhance the outcomes for both the firm and the end consumer. This dual benefit is attained through the production and delivery of "offerings that have value" (AMA 2008) to the consumer and to business stakeholders at large. Specifically, empowering managers to bring relevant consumer-self insight into marketing decision making may assist firms to meaningfully navigate the potential value creation and co-creation processes towards developing strategic competitive advantage.

\section{Conceptual Background}

A significant shift has occurred in our understanding of what value is and how it is created. Disparate streams of contemporary management and marketing research have examined the processes and loci of value creation - how and where value is created and extracted for the end consumer (Cova, Dalli, Zwick, 2011; Grönroos and Voima, 2013). This wave of theorizing and empirical research has built a common platform from which to reframe value creation from a company-centric notion where firms embed value into the consumer offering that is then passively extracted by the consumer, to an ongoing process of value creation through interaction between the consumer, the producer, and the good/service.

This platform initially emerged from within the management literature. Normann and Ramírez (1993), then Prahalad and Ramaswamy (2000, 2004a, 2004b), theorised a new logic of value underpinned by a shift in the loci of value creation in response to changing consumer expectations of companies and the products/services offered (Cova et al., 2011). This consumer transformation has changed the rules of the marketing game. Prahalad and Ramaswamy (2004b) conceive that contemporary consumers expect to have an open dialogue with companies and to infiltrate the production cycle, rather than passively being segmented 
and marketed to. Thus, value is co-created through a process in which "the consumer and the firm are intimately involved in jointly creating value that is unique to the individual consumer...The interaction between consumers and firms becomes the new locus of cocreation of value" (Prahalad and Ramaswamy 2004b, p 16). The locus of value co-creation in this conception is limited to the point of exchange. Fournier and Mick (1999) discover, however, that the meanings and value extracted by the consumer during their ongoing interactions with the offer extends beyond the point of exchange and can transform over time.

Academic and practitioner interest in value co-creation has since spread, sparking burgeoning literature streams within the broad marketing domain. The shift of loci of value creation to outside of firm operations is a common thread between these related marketing streams. Arguably, the dominant co-creation stream within marketing to date is the Service Dominant Logic (S-DL) framework (Vargo and Lusch, 2008; Vargo and Lusch, 2004). Vargo and Lusch (2004) responded to paradigm fragmentation of the marketing discipline by proposing an overarching service-based framework to thread the discipline together. They propose a marketing paradigm shift from the traditional goods-centred view to a servicecentred view of consumer value creation. The traditional view of value creation centres on the firm embedding value into goods within production processes that are separated from a passive end consumer. In contrast, Vargo and Lusch's (2004) service-centred value creation logic focuses on interactions between firms, customers and the offer, and removes the distinction between goods and services by considering the service/solutions that goods provide. This view presents value creation as a dynamic collaboration between the customer and the firm. In this sense, firms are limited to the creation of value propositions; "the consumer must determine value and participate in creating it through the process of coproduction" (Vargo and Lusch, 2004, p 11). 
The notion that producers, consumers and the good/service offering are inseparable in the creation of value is inherent to the S-DL framework. The S-DL model does not, however, explain the differing and contextual roles of these entities in the ongoing process of value creation (Grönroos, 2011). Grönroos (2011) seeks to address this limitation by theorising three scenarios of value creation: (1) the production of potential value when the firm interacts with the offer in isolation; (2) the co-creation of actual value when the firm, consumer and offer coalesce; and (3) the creation of actual value when the consumer interacts with the offer in isolation from the firm. In this conception, producers are generally only capable of investing potential value that is latent in consumer offerings in isolation from the consumer. In addition, the only possible locations of co-production and value co-creation are the points of interaction between the company, the offering, and the consumer; for example, interactions with frontline staff at the point of exchange (co-creation), and points of interaction when consumers are drawn into the innovation funnel (co-production). In isolation from the company/producer, consumers create value-in-use when they interact with the item or service. This three-domain approach to value creation takes a consumer-centric view (Grönroos and Voima, 2013), drawing upon a growing customer dominant value creation literature stream (e.g. Heinonen, Strandvik and Voima 2013; Anker, Sparks, Moutinho, and Grönroos 2015) to privilege the end consumer in the mechanics of value creation. This customer dominant perspective also represents consumer experiences of value creation to be contextually-bound and contingent on the momentary situational context (Belk 1978), such as the temporal, social, physical and psychological environment.

Consumer culture theorists have also extended the S-DL by studying value creation experiences in consumer communities and the creation of brand meanings (e.g. Schau, Muniz and Arnould, 2009; Giesler, 2012; Pongsakornrungsilp and Schroeder, 2011), taking a particular interest in how communities of consumers collaborate to co-create value, with and 
without interactions with the company. The notion of co-creation has also raised the interest of marketing critical theorists, who illuminate the potential negativities of producer-consumer value co-creation. Value creation is generally conceived as a positive process that increases the consumer's well being (Vargo and Lusch, 2008). Echeverri and Skålén (2011),Plé and Caceres (2010), and Zwick, Bonsu, and Darmody (2008) illustrate, however, that not all value creation is beneficial to the end consumer - indeed, value can be destroyed. In this conception, value destruction and co-destruction can occur when fundamental priorities of the firm and the consumer are not aligned. This research has opened up a promising and more complex view of the co-creation of value, with the outcome of this process being a spectrum of possibilities between value creation and value destruction.

Value creation and co-creation are generally viewed within this developing body of conceptual and empirical research as collaborative processes between the discrete entities of the firm, the good/service, and the consumer. In response, Ritzer, Dean and Jurgenson (2012) call for co-creation research to take a more fluid - rather than binary - stance, to recognise that by the very nature of markets and consumption, consumers are often also producers. They advance the concept of the prosumer "who is both producer and consumer" (p 379). Ritzer et al. (2012) contend that this notion of prosumption is not new, with scholars as early as Marx theorising that production and consumption are fundamentally interrelated and that an individual could both produce and consume (Cova et al., 2011).

Advances in value creation research have moved the field to consider a more amorphous representation of the consumer also as a producer. Treatment of the 'firm' remains static, however, maintaining a dichotomous relationship between 'the firm' and the consumer (e.g. Arvidsson, 2011). Prahalad and Ramaswamy (2004b) suggest "unfortunately, most managers seem to forget that they are also consumers" ( $p$ 37), and it seems that marketing researchers have also forgotten this reality. The entity of the firm is broadly 
considered as a 'producer' of potential value, but is yet to be inversely conceived as also being a consumer. We contend that this entrenched firm-consumer dyad does not realistically reflect the experiences of individual managers within the firm, and has artificially constrained research of the 'firm' within the value creation dynamic to organisational-level only.

In this study, we problematise current notions of value creation and co-creation, specifically illustrating two key limitations. First, viewing the producer at 'firm' or organisational level ignores the role that individual managers within the organisation play in making decisions that impact on the creation of value. We contend that this approach limits the granularity of our understanding of value creation and co-creation processes and creates a view that misses an important component of value creation. Second, in our consumptiondriven society, the daily practices of individual managers within organisations are laden with consumer derived priorities, as illustrated by Keith in the introduction. Failing to acknowledge that these individuals have consumer-based roles inside and outside of their work and that the boundaries between work-self and consumer-self may be somewhat amorphous, limits our understanding of consumer-driven value on production decisions.

We address extant limitations of value creation and co-creation knowledge with the following three study aims: (1) to explore potential value creation at an individual/manager level of analysis from a vantage point within the firm; (2) to investigate the impact of infiltrating one's work domain with personal consumption ideals on marketing management decision making; and (3) to examine the influence of the organisational context on the pervasiveness of individual's consumer ideals in managerial practice. Vargo et al. (2008) acknowledge that many unanswered questions remain, including "what exactly are the processes involved in value creation?” (p 151). Further, Prahalad and Ramaswamy (2004) contend that the single most profound shift that companies and managers must make in the age of value co-creation is to "recognise the centrality of the individual. It does not matter 
whether we are dealing with a consumer, an employee, an investor, or a supplier" (p237). They also suggest that disconnect between "company think" and "consumer think" must be bridged for firms to achieve success in the contemporary market place. Our approach has a mandate and specific significance for marketing academic and practitioner audiences.

In this article, we align with Grönroos's (2011) and Grönroos and Voima's (2013) consumer-centric conception that producers create potential value within firms, consumers create actual value-in-use in isolation from the firm, and that co-production of the market offer and value co-creation only occur when and where firms and consumers interact. We nevertheless integrate these three value creation scenarios by considering marketing managers as both producers and consumers. In doing so, we contend that the actions of significant marketing decision makers within the firm, individually and collectively, exert a meaningful impact on overall firm behaviour and performance. This contention is reflected in the scope and impact of decisions made by the informants in our study.

In this article, we first outline the in-depth qualitative methodology employed to investigate the role of individual managers-as-consumers in the creation of 'ethical' potential value latent in consumer offerings. Next, we combine four themes emerging through our data and analysis with boundary theory from sociology (e.g. Nippert-Eng, 1996) and management/organisational studies (e.g. Ashforth, Kreiner, and Fugate, 2000) to extrapolate and synthesise these findings to develop an integrated model of producer-as-consumer potential value creation. This model reveals the mechanisms underpinning the integration of managerial and consumer-self insight to co-produce potential value in market offerings. As the creation of actual value-in-use by the consumer is contingent on the production and coproduction of potential value embedded in the market offering, this process has significant implications for marketing operations and firm competitiveness. 


\section{Research Methodology}

We address the three research aims through an in-depth qualitative study involving 25 marketing managers and directors. The study is situated within the context of 'ethical' production and consumption. We chose this context as the salience of an individual's personal consumption ethics beliefs provides an ideal scenario to investigate the cross-over of this conscious belief system into workplace decision making. Personal ethical concerns regarding consumption may include various issues such as fair trade, environmental impact, animal welfare, and child labour.

\section{Methods and Sampling}

The emergent state of the literature examining the role of individual marketing managers/producers in the value creation dynamic indicates qualitative research and inductive analysis as an approach of best fit to develop theory to address the present research aims and literature gap (Edmondson and McManus, 2007). Thus, the study employs a multisited, multi-method ethnographic approach within the business context (Arnould and Wallendorf, 1994), through which we immersed in the workplace lives and environments of the 25 informants. We combine semi-structured ethnographic interviews, participant observation, and informal interviews within the single study (Hammersley and Atkinson, 2008). All interviews were conducted at the participant's sites of work, including corporate offices, retail outlets, and on the factory floor, and were one to four hours in duration. Meeting and interviewing participants at their work places facilitated natural responses within context. Participant observation also occurred in informants' working environments, and ranged from observing corporate artefacts and clothing choices within this environment through to participating on the retail and factory floor. Observing corporate artefacts - such as achievement awards hanging on walls and the presence of recycling and compost bins (or 
lack of) - combined with interview data, assisted in the analysis of organisational culture and expectations in the context of our study aims.

The study was multi-sited, moving across multiple organisations, industries and countries (Kjeldgaard et al., 2006) to gain an in-depth understanding of consumer-self infiltration of the workplace that is broadly applicable. We employed a maximum variation sampling strategy (Miles and Huberman, 1994) with a participant pool consisting of: major and minor retailers; large, medium and small production firms; multiple industries; national and multinationals; managers from the US, Australia, and the UK (Table 1). Consistent with this sampling strategy, these organisations varied in their support of ethical causes from companies that have been built on an ethical platform, through to organisations for whom ethics and CSR are merely included as a bullet point on the company mission, if at all.

\section{Data Analysis}

Our analysis takes an inductive approach. Data was initially open coded using a micro-coding technique (Corbin and Strauss, 2008) as the data was being collected (Hammersley and Atkinson, 2008). Key concepts were developed from these micro-codes using Spiggle's (1994) abstraction analytic method. We moved to macro-coding and analysis using a constant comparative technique to challenge and further develop these concepts and relationships (Corbin and Strauss, 2008). In the first phase of the research, we collected data from 13 informants until theoretical saturation was reached. We then consulted the literature on boundary theory, workplace identities, and value co-creation to frame and position our findings. The second data collection phase comprised 12 informants, where we sought further variation and negative cases to challenge and extend the emerging theory. 
We combined maximum variation sampling with several strategies to ensure data quality and credibility of the analytic interpretation, including: data triangulation through multiple methods; constant comparative and negative case analysis; regular team debriefs; and, consultation with colleagues not involved in the study (Hammersley and Atkinson, 2008; Miles and Huberman, 1994; Wallendorf and Belk, 1989).

\section{Findings and Discussion}

Our overarching goal is to reveal the extent to which a marketing manager's own priorities as a consumer infiltrate their workplace decision-making, and how this interplay between consumer-self and manager-self implicates potential value creation for the end consumer. Our data and analysis reveal four key insights that address this study goal. First, we establish the situational conditions that enable marketing managers to integrate consumer-self into managerial decisions. Second, this variation in this consumer-self integration is largely contingent upon the level of alignment/congruence with managerial and organisational priorities. Third, marketing managers dynamically prioritise multiple elements of value on a case-by-case basis to optimise the potential value embedded in the market offering. Finally, marketing managers actively work to re-negotiate the interplay between manager and consumer domains to reduce conflict between these realms. This coping mechanism dynamically impacts the elements of potential value for the end consumer embedded in the offering.

In this section, we submit our findings in detail and concurrently draw on boundary theory (Ashforth et al., 2000; Nippert-Eng, 1996) to extrapolate beyond these findings to derive a producer-as-consumer potential value creation model (Figure 1). This potential value creation model creates a new lens through which to understand the complex role of the firm in value creation and co-creation at an individual level, and provides a framework for 
marketing managers to reflexively consider the impact of the consumer-self on their own and their firm's value creation.

\section{INSERT FIGURE 1}

Boundary theory is central to our theorization and development of the producer-asconsumer potential value creation model. Boundary theory explains how individuals create, negotiate, and maintain multiple spheres/domains within their life experience and the relationships between these domains (e.g. work and home). Boundaries are enacted, adapted and maintained by individuals to simplify and provide order to their life (Ashforth et al., 2000; Nippert-Eng, 1996). The ongoing construction of these boundaries results in the definition and delineation of domains that are meaningful yet fluid categorizations to the individual (Ashforth et al., 2000). To date, marketing literature has studied sub-sets of self/life domains and the boundaries that delineate them - in particular consumer research studies of identity and identity work (e.g Moisio, Arnould, and Gentry, 2013). We know little, however, about the broader context of life domains, the relationships between domains, and the dynamic boundaries that contain them.

Nippert-Eng (1996) suggests that the domains of work and home are so interdependent that they must be studied and understood together. These domains dynamically interact, blend and intrude on each other along a continuum of experiences and across multiple interfaces that are unique to each individual (Kreiner et al., 2009). We extend this conception to suggest that to understand potential value creation and co-creation from the firm's perspective at an individual level of analysis, we must explore both the individual's managerial and consumption domains together and the relationships negotiated between them. We now combine our findings with insights from boundary theory to develop our producer-as-consumer potential value creation model. Specifically, we draw on the concepts of boundary permeability, domain congruence, domain segmentation and integration, and 
boundary work. First, however, we detail how the managers in our study bring their consumer-self into work and managerial practice.

\section{Integrating Consumer-self into the Workplace and Work Practices}

Mark: Ultimately, I'm a consumer like everybody else, and I have to make choices according to my [own] considerations.

Like Mark, our informants reveal the centrality of consumption to their lives - inside and outside the office. During the study, we observed marketing managers integrating their consumer-self ideals into their daily managerial practices. This consumer-self influence was exercised consciously in practices such as making personal judgement calls on acceptable supplier operations, refusing to pass increases in raw material costs on to end consumers, and choosing to produce and market products that they personally liked. We also observed subconscious manifestations of overlaps between consumer and work self in practices such as the routine wearing of 'casual' clothing at work. For instance, Carla was observed wearing bicycle lycra underneath a lab coat out on the factory floor, and Keith is just as comfortable conducting high-level business meetings in a local café as he is in his boardroom.

Statements of personal ethical consumption concerns and practices were a prominent feature throughout the study; the extent to which these concerns infiltrate their managerial practices, however, varied significantly. At one end of the spectrum, we discovered managers, such as Richard, who routinely bought their consumer-self into work.

Richard: A lot of people separate business. They separate business and their feelings as two completely separate things. Whereas mine are very, very much integrated. A lot of people will be just like that completely [Richard holds up his hands with fingers made into two separated circles], whereas I am - well the whole area is overlapped [Richard merges the two finger circles together like an overlapping Venn diagram]. I wear my heart on my sleeve, and I bring that to work. 
At the other extreme end of the spectrum, we encountered managers - such as Jonathon - who metaphorically leave their consumer-self in the car park as they enter the work space. While these informants were able to articulate their own personal ethical concerns as consumers, they saw little place for these issues in their day-to-day business decisions. This delineation of work and consumption life does not mean, however, that they don't contemplate their consumption priorities in managerial contexts. For example, Jonathon illustrates the pervasiveness of consumer-self and experiences of discomfort with conflicting managerial-consumer priorities despite maintaining a separation between these domains.

Jonathon: At the end of the day we work for the company, and for the company to stay in business and make money, so we're about selling as many [X's] as we can. Whereas, from a personal point of view, as an ethical consumer, yes, I would much prefer that we bought a lot less junk. I do have a little difficulty sometimes trying to balance that off.

Most informants, however, vary between these two extremes, bringing consumer-self into the workplace, yet intermittently exercising this realm in managerial practice. For example, Nicholas illustrates the dynamic and negotiated nature of the intersection between consumer-self, manager-self, and the organisation.

Nicholas: There's a line around them and when you are making decisions at work you have to say, okay, they're my personal views. Then you have a box that says these are my client's views, and you have a box that says these are my company's views. I definitely think that it's an intersection of all three. That intersection will change depending on what the subject is, or who has more influence.

We now draw on the notions of domain congruence and boundary permeability (Nipper-Eng, 1996) to explain the overlap of priorities and ideals between consumer-self, manager-self, and the organisation displayed by marketing managers in our study.

The Impact of Domain Congruence on Internal Boundary Permeability. In her seminal boundary theory study, Nippert-Eng (1996) describes the contemporary predilection to 
categorise life and self into multiple domains of experience - in particular the seemingly dichotomous realms of work and home. Once cognitive boundaries are constructed to define and contain categorical domains, the individual then works to express and reinforce these mental domains in the physical and symbolic world (Nippert-Eng, 1996). In the context of our study, we conceptualise the internal categorical domains of manager-self and consumerself.

The boundaries that define and segment domains can vary in function; from impregnable barriers completely separating two categorical realms, to porous boundaries that allow seepage between domains (Nippert-Eng, 1996). Boundary permeability describes the degree to which a boundary allows elements from one domain to enter and influence another intersecting domain (Hall and Richter, 1989). In the initial construction of a shared boundary to delineate intersecting domains, it is the level of similarity or congruence between these two domains that determines the permeability of their border. The higher the congruence between the intersecting domains, the more permeable is their shared boundary (Nippert-Eng, 1996). Congruence between domains can relate to any of the symbolic and physical elements contained within. Thus, while some parts of the boundary may be impregnable and difficult to cross-over due to incongruence, other portions of the boundary allotted to highly congruent domain elements may be completely open to two-way domain contamination (Nippert-Eng, 1996; Kreiner et al., 2006).

Drawing on domain congruence and boundary permeability to extend the findings presented above, we theorise that marketing managers who experience a high level of congruence between their managerial priorities and consumer ideals - such as Richard - will construct relatively porous boundaries between these internal domains. For these individuals, the transition between work-self and consumer-self is seamless, and can occur in workplace situations - such as informants who unconsciously flip between referring to themselves as 
consumers and as marketing managers during interviews (e.g. Richard, Mark Diana, and Megan). In contrast, marketing managers who experience high levels of incongruence between their internalised managerial expectations and consumer ideals constructed impregnable boundaries that can only be crossed with personal effort, if at all. Thus, we contend that the permeability of intersecting sections of boundary between an individual's internalised/cognitive work and consumer domains is a function of the similarity or congruence between elements of these domains (see Figure 1).

The managers in our study were not acting in seclusion, however. The culture and priorities of the organisations in which they worked significantly influenced the levels and locations of overlap between their managerial and consumer domains. We now explore this external influence.

\section{Organisational Fit and Acceptance of the 'Whole-Self' at Work}

The organisations in which our informants worked provided direction - implicit and explicit - on the extent to which they were to bring their 'whole-self' to work, if at all. For example, Andy illustrates the role of implicit corporate culture in permitting his own sustainability concerns to infiltrate workplace decisions: "it's [sustainability] closely embedded in the company and therefore there is a high degree of support for things like that'. Informants' organisations developed and enforced guidelines that both reinforced the organisational values and influenced normative expectations of consumer-self integration into managerial practice. For example, Roland explains how his company has: "been very effective at creating a culture that makes employees aware of our responsibilities as citizens of this planet. At every stage we are reminded of that responsibility".

The financial goals and business model of the firm played a significant role in determining the limits of acting on personal consumption ethics in managerial practice. 
Consider the following interview excerpt that reveals the impact of the firm's financial expectations on the merging of producer-consumer domains.

Meagan: It is a balancing act. At the end of the day we're a public company and we answer to shareholders. So sometimes I have to make decisions because I have to make those decisions... But I believe that we weigh more heavily on the side of the right thing to do.

Informants such as Meagan reveal a balancing act: seeking to weave their consumer-self into management decisions, while being constrained by contesting priorities of their firms. This balancing act is a constant negotiation between the individual and the firm.

In contrast, Simon works in a privately owned and run company. In the following interview excerpt, Simon describes his permissive organisational environment.

Simon: I don't have to really worry about convincing people - I don't have to go there... I think it's a perfect role for me because not only do I live and breathe sustainability and enjoy learning as much as I can about what the issues are surrounding it; I can take those messages and those concerns and bring it to our ownership and to our manufacturing centres...and incorporate new ideas.

Working within permissive firms and teams with congruent priorities, such as Simon's and Andy's, enabled informants to blur the boundaries between manager and consumer to some extent. We now extend boundary permeability and domain congruence theory to the intersections between the individual and their organisation.

The Impact of Organisational Permissiveness and Domain Congruence on IndividualOrganisation Boundary Permeability. Managers within organisations are not operating and making decisions in isolation. These individuals are embedded in physical and social work settings that are loaded with culture, structure, strata, expectations, and other situational influences (Ashforth et al., 2000). Our study reveals the intersections between marketing managers' work and consumption practices to be highly influenced by the norms, goals, and 
ethos of their organisation. It is at this individual-organisational boundary interface that the nature and location of the boundaries between the individual and the organisation are constructed and negotiated (Kreiner et al., 2006). Just as the boundaries segmenting an individual's internal domains vary in permeability, it follows that the externalised individualorganisational boundary is also subject to variations in permeability and integration. In our study, we discovered the permeability of the individual-organisation boundary to be influenced by: (1) organisational permissiveness of bringing the consumer-self into the workplace; and (2) congruence between the priorities of the firm and the individual.

Prior boundary work studies in sociology and organisational behaviour have found that highly regimented, authoritarian, individualistic and competitive work environments foster segmentation of domains and impermeable boundaries between work and home in workplaces (Kreiner et al., 2009; Nippert-Eng, 1996). In contrast, integration between work and other domains of life is fostered in organisations that maintain flat structures, encourage collectivist work practices, empower individuals and teams with decision making, and accept flexible working practices (Ashforth et al., 2000; Nippert-Eng, 1996).

Further, in their study of the interfaces between individual and organisational identities, Kreiner et al. (2006) suggest that permeability of the individual-organisational boundary and the extent of domain integration between the individual and the organisation is contingent upon the individual's perception of congruence or 'fit' with salient aspects of the organisational identity. Thus, blurred boundaries and merging may occur between elements of the individual-organisational domains that are congruent. In contrast, impermeable boundaries and domain exclusion may result where domain contents are incongruent.

Combining these conceptions of organisational permissiveness and individualorganisational congruence with our empirical data, we contend that the permeability of the individual-organisational boundary is underpinned by both: perceptions of 'fit' between 
salient aspects of consumer-self and the organisation; and, organisational culture. The higher the perceived congruence between self and organisation, the more permeable the individualorganisation boundary at this intersection point. In addition, the permeability of the individual-organisational boundary is also reflective of organisational permissiveness of integrating consumer-self into managerial practice. These relationships are depicted in Figure 1.

We now explore the impact of boundary permeability at the intersections between consumer-self, manager-self, and the organisation on the extent to which consumer-self is integrated into managerial decisions.

\section{Domain Integration: Merging of Consumer and Managerial Priorities}

Simon: They're so intertwined, I don't even really have to think about them or separate them.

Gabrielle: I don't know where my own personal insights as a mother and the research begin and end. Because in 20 years of talking to mums, understanding mums, it's really hard to understand where my personal opinion is versus what I know from the research to be honest. I'm sure that has [influenced] the type of mother I am. So I think it's a symbiotic relationship.

Domain Integration-Segmentation Continuum as the Outcome of Boundary Permeability.

Nippert-Eng (1996) conceives that the overlap between an individual's work and home domains can be conceptualised on a continuum. We adapt this continuum to the consumption and managerial realms. At one extreme of the continuum, work-self priorities and consumer-self ideals are completely integrated - as is the case for informants such as Simon and Gabrielle. For these individuals, consumer and manager/producer domains are inseparable and merged in content, values, and meaning. These individuals interpret and experience work and consumption through the same lens, behave and respond in the same 
way in most situations, and would view all space and time as legitimate situations to engage in managerial and consumption related activities (Nippert-Eng, 1996).

The partial or full integration of consumer-producer domains is a result of permeable boundaries (Ashforth et al., 2000) that leak and allow selected seepage across domains. Interestingly, we discovered examples of bi-directional domain contamination across highly permeable consumer-manager-organisation boundaries, as illustrated by Meagan and Nicholas.

Meagan: I think a lot about what we eat, and that is impacted because I work in an agricultural industry. When I take that home, what it means to me is: how were the farmer's treated, were they paid fairly for what they were growing? I feel like as a company we are doing the right thing and that transcends home, am I doing the right thing at home. I think [company] has given me the ability to look on the flipside which is not just is it good for me but is it good for the environment. Is it good for the folks who grew it or tested it? Is someone being harmed on the other side? I think that they've really given me the lens of looking at the bigger picture. I think that the organisation has taught me a lot...the more and more you hear about it, it just becomes ingrained and you take it home. There is no question that you take it home - it impacts the choices you make at home.

Nicholas: I've changed over time and I think I've been influenced by the workplace massively. You get on the bus and you get dragged along by it.

Informants' articulation of the influence of their organisation and manager-self on personal consumption choices reveals permeability of these boundaries and directional variation in the contamination of ideals across the intersection of work and consumption.

At the other end of the continuum, managerial practices and consumer-self are completely segmented. While extreme segmentors, such as Jonathon and Bethany, acknowledge the overall centrality of their consumer domain to life in general, the ideals contained within this consumer realm are not integrated into managerial practices. Work-self and consumer-self are experienced as mutually exclusive realms of life in a Jekyll and Hyde existence (Ashforth et al. 2000; Nippert-Eng 1996). Highly segmented domains are created by defined and impermeable boundaries that block the diffusion of elements across domains. 
In reality, we discovered that individual managers have numerous elements within their managerial and consumer domains that vary along the spectrum of integration and segmentation, underpinned by elements of varying congruence and incongruence between domains. Thus, we contend that the permeability of the boundaries between an individuals' consumer-self and manager-self plays a determinant role in the extent of consumer-producer domain integration at these intersections. This integration can be bi-directional.

The extent of merging between consumer ideals and managerial practices was also contingent, however, on the intersections between the individual and their organisation. Organisational-level priorities determine managerial priorities. Thus, we also theorise that the permeability/impenetrability of the intersections between the consumer-self and the external organisation influences the interplay and integration between consumer-self and manager-self (see Figure 1).

We now consider the influence of this producer-consumer duality on the creation of potential value.

\section{Potential Value Creation as the Outcome of Domain Integration-Segmentation Continuum}

Marketing managers produce potential value (Grönroos and Voima 2013). Through managerial decisions and practices, the marketing function instils the potential for the end consumer to create ongoing value through their interactions with the product, experience, service and/or brand. Thus, marketing managers - acting within the bounds of the organisation - have the agency to determine which elements of potential value are instilled and latent within the market offering. For example: instilling the potential for consumers to extract status-value when interacting with a luxury brand, or the potential to create ethicalvalue when purchasing free-range eggs. 
The extent of integration between their consumer-self and manager-self played a significant role in determining the nature of potential value infused by our informants in dayto-day production/marketing decisions. Drawing upon Grönroos and Voima's (2013) conception of firms as value facilitators, we observed informants integrating consumer-self priorities into decision making across the broad production functions in a co-production process: design, development, manufacturing, and delivery. Consumer-self priorities were often juggled, however, with other inputs into the potential value creation process, such as market research, as informants worked to embed elements of potential value into the offering that they believe will be desired by the end consumer. Consider Robert's experiences of 'resonance' working in a co-operative retail outlet.

Robert: I'd say local production would be the biggest concern for me. The next would be animal welfare. I am very fortunate to live in a city and work in a company that these are also priorities for them...resonating with my own morals and values. Every time I go into the store and put a tag up on a product or a producer profile that mentions something about our values - whether it be organic, ethically and sustainable animal products, it just makes my soul feel better, knowing that I'm doing good work in that regard.

Robert articulates a sense of inner coherence that makes his "soul feel better", a result of the alignment experienced between his personal consumption ethics and the values of the cooperative. Robert's merging of consumer-producer domains manifest in the infusing of consumer-self values into the products the firm offers on the retail shelves. For Robert, not only do the goods offered in his firm's stores embody highly salient aspects of value for him personally, but he also senses that he is facilitating desired value creation for the customer. This is further articulated by Keith.

Keith: It's very much in the DNA of what [the company] does. While I don't talk openly about [the company] being deliberately ethical, it's implicit in everything that I do. I don't see it being the only reason why people buy the product, but I see that as the reason why they connect meaningfully and emotionally to the product. My product operates on that sort of superficial level of being nice to look at and attractive, but I desperately hope that they 
have a deeper connection with the product because [they] truly believe in treading lightly on the earth.

In stark contrast to Keith and Robert's integration of personal ethical values into business decisions, other informants segment their consumer and work domains into two separate spheres of existence. In these cases, we observed individuals working to imbue the end product or customer experience with the elements of value prioritised by the organisation and other inputs/stakeholders, with seemingly little concern for their own consumption ethics.

As adept as informants were at juggling multiple stakeholders and complex relationships between their personal ethics, managerial imperatives and organisational directives, the intersection of these complex interests in managerial decision-making sometimes led to situations of tension and conflict, illustrated by Michael in his discussion of the production and transport (carbon miles) decisions involved in launching a new range of 'green' cleaning products.

Michael: I probably haven't been the greatest advocate for it, because I've been rather disappointed to think we've had to source them from overseas...An argument that I have within my business all the time is that we might have the highest standard and have a great product, but it has to come from the other side of the world. Whereas one that is 90 per cent as good comes from a factory only 20 minutes away. So, it's that trade-off all the time. [My preference] would be to work with these [local] suppliers to get them to that right standard. And maybe our standards are too high; the consumers are not even looking for this.

In these situations of interplay between conflicting priorities, informants such as Michael were dynamically juggling and prioritising elements of value to themselves and to their stakeholders - including the end consumer - to determine the most salient elements of value on a case-by-case basis. For informants who bring consumer-self into work, misaligned business priorities and the trade-offs inherent in complex managerial decision making often results in less than ideal production outcomes. In these situations, informants sense that by trading-off against their own consumer-self priorities they are also diluting the potential value 
instilled in the offering for the end consumer. Thus, illustrating a contrasting scenario of potential value destruction (Echeverri and Skålén, 2011).

We theorise that the marketing manager's choice of which elements to invest as potential value in the consumer offering is influenced by the level of integration of consumerself into this managerial decision. Drawing on Gronroos and Voima's (2011) notion of coproduction in the interactions between producer and consumer, we theorise that scenarios of consumer-self integration into marketing managerial decisions represent situations of coproduction where the internal consumer-producer selves jointly determine the elements of potential value embedded in the market offering. Our findings show that consumer-self is omnipresent in the work space for managers who have highly integrated consumer and work domains (e.g. Keith, Simon and Richard). In contrast, marketing managers who have partially integrated work and consumer domains bring a monitored and constrained set of consumerself elements of value to their managerial decision making (e.g. Megan, Michael and Andy). This results in partial and/or sporadic investment of potential value in the end consumer offering that appeals to their consumer-self priorities. Thus, scenarios of internalised producer-consumer co-production are contingent and variable. Additionally, marketing managers who experience highly segmented work and consumer lives do not expect to instil personally appealing elements of potential value into consumer offerings unless prescribed by their firm's strategic priorities and expectations (e.g. Jonathon, Bethany and Martin).

In summary, we theorise that the consumer-producer integration/separation continuum has a determinant impact on the extent to which personally significant elements of potential value are instilled and latent within the market offering. This contingent relationship between consumer-producer domain integration, internalised producer-consumer coproduction, and the subsequent nature of potential value embedded in the end consumer offering is illustrated in Figure 1. 
The intersections between consumer-self, manager-self, and the organisation, however, are not static. Rather, we observed the marketing managers within our study actively working on and altering the location and permeability of boundaries between internal and external domains; in effect, changing the nature of the boundaries and domains themselves. We now explore this observation of marketing managers as active boundary workers.

\section{Dynamic Interplay between Work and Consumption}

Our informants were not passive players simply responding to external organisational priorities and pre-negotiated static points of intersection between consumer-self and managerself. We observed active agents pushing, pulling, stretching and constructing dynamic intersections between their consumption ethics and management priorities within a variety of organisational contexts.

Boundary Work as a Conflict Management Strategy. $\quad$ Extrapolating these findings, we theorise that marketing managers actively engage in boundary work (Nippert-Eng, 1996) to construct, maintain, negotiate, and re-construct the intersections and interactions between work-self and consumer-self. The definition and interaction between these two domains was dynamic and often contingent on the momentary situation or decision making scenario. Thus, the interplay between an individual's manager-self and consumer-self can be conceived as a dynamic jostling with the intersections being pushed, pulled and stretched; thereby shifting levels of integration and segmentation. Engaging in active boundary work enables individuals to either: strengthen the impermeability of the borders to further separate the domains; or, dissipate sections of the border between work and consumer realms to increase the permeability and further integrate the domains (Kreiner et al., 2006; Nippert-Eng, 1996). 
We discovered marketing managers engaging in active boundary work as a conflict management strategy, attempting to re-negotiate and re-construct the internal producerconsumer boundaries and the interfaces with the external organisation in response to incongruence or conflict between domains (Kreiner et al., 2009). In our study, these boundaries were weakened to allow the contamination of priorities, ideals, expectations across domains. This boundary work occurred at either the internal intersections between manager-self and consumer-self (internal locus), or at the intersections between the individual and the organisation (external locus).

Internal Locus Boundary Work. Some informants work to reduce conflicting consumerproducer demands by diluting these domain boundaries to integrate more of their consumerself in managerial decisions in ways acceptable within their firm. We observed numerous manifestations of this boundary dilution work. For example, the use of discursive integration - such as referring to themselves as the singular 'I' (rather than 'we') in the workplace context - was a common boundary work tactic amongst our informants to identify with their consumer-self and increase the merging of these domains. Roland also displays internal locus boundary work when cognitively bringing concerns for his own children into his marketing decisions.

Roland: I always think of my family. I've got kids. I wouldn't do anything to harm them. That's an over-riding guiding principle, be it mentally or physically. If I know that an advertising [campaign] is going to [impact] my kids - no, I will not do that.

In contrast, some informants - such as Lucas, Martin and Jonathon - work to further develop or maintain the separation between their own consumer-self and manager-self as a means to "leave to one side" (Jonathon). In these scenarios, informants worked to pull back the influence of their consumer-self in the work space, thus reducing experiences of conflict 
within complex production decisions. Withdrawing the consumer-self from marketing decisions also reduced informants' personal investment in the nature of 'value' created when the end consumer interacted with this market offering.

External Locus Boundary Work. Though less prominent, we also observed marketing managers engaging in boundary work to influence externally located (external locus) factors inhibiting the integration of consumer-self into marketing managerial decisions organisational acceptance and the congruence of external/organisational priorities. Indeed, we witnessed participants, such as Anita, engaging in boundary work tactics to change organisational expectations and shared boundary permeability. For example, Anita works in a publically listed company answerable to shareholders, where bringing consumer-self to the decision table is not an accepted practice. Yet, in this corporate context, Anita manages to inconspicuously thread personal consumption ethics into daily managerial practice by employing covert tactics. She creates and deploys social and environmental guidelines that are based on international standards, but are also covertly loaded with in her own consumption ethics.

Anita: We base a lot of our expectations on international standards, so that acts as the backbone, and then I try to write policies, procedures and guidelines that encompass that, plus things I would like to see.

Her superiors are not aware that these additions are not part of the international standards, which gain business approval due to their industry legitimacy. These endorsed guidelines are then used as a pathway to integrate her personal ethical preferences into business decision making that may otherwise be viewed as an unacceptable practice. In this sense, Anita is employing covert tactics to enable her to instil ethical value that is salient to her in the products sitting in her company's retail stores. 
The strategising and deployment of boundary work tactics enables the individual to dissolve sections of the interface with their organisation, allowing their own ideals and expectations to seep into the contents of the organisational domain.

Variations in Boundary Work Response. The boundary work responses of marketing managers within our study varied significantly between situations and individuals. We construe this variation as a continuum of boundary work tactics employed by individuals to manage domain conflict (Figure 2). At one extreme, highly active individuals overtly work to increase the extent of integration between their managerial and consumer-self domains. This boundary work is focused on dissipating boundaries at the intersections with the organisation or the internal boundaries between manager-self and consumer-self. The purpose of this assertive form of boundary work is to increase the congruence between work and consumer domains through the diffusion of salient aspects of the consumer-self into the work domain. Robert displays this extreme form of boundary work when he describes himself as being the "one who challenges anything that comes to me, [putting] it through the mill to see how it turns out".

At the other end of the continuum, individuals employ boundary work tactics to reduce experiences of internal tension by increasing the extent of separation between their managerial and consumer categorical domains. For instance, discursive separation - such as using the term 'we' rather than 'I' to identify with the firm, and 'they' when referring to the collective consumer - was a common boundary work tactic used to withdraw individualised priorities from the workspace. In the most extreme cases of separation, the individual may choose to withdraw themselves from the workplace completely. As an example of this extreme withdrawal boundary work, Richard suggests: "I worked for a business that basically did things that I couldn't deal with. I could not just stand by, I challenged them on it a 
number of times and they just dismissed it. I left". Figure 2 details the continuum of boundary work tactics embedded in our Producer as Consumer Potential Value Creation Model (Figure 1).

\section{INSERT FIGURE 2}

Boundary Work Implications for Potential Value Creation. Opening the barrier and allowing seepage between domains worked to reduce conflict by increasing the similarity congruence - between intersecting categorical realms. In contrast, strengthening the barriers between intersecting consumer and work domains and/or individual and organisation domains enabled conflict management by further separating the domains into compartmentalised categories to eliminate the source of conflict all together. Pulling back and/or pushing forward the intersections between consumption and production, coupled with evolving business priories; results in a dynamic spectrum of potential value creation possibilities. This active engagement in boundary work frames our 'Producer as Consumer' potential value creation model (Figure 1) as dynamic and contextually derived.

\section{Conclusion}

Current conceptions of value facilitation, creation, and co-creation consider how the ongoing interactions between the producer (firm), consumer, and good/service create an evolving sense of value (e.g. Grönroos and Voima, 2013; Schau, Muniz and Arnould, 2009; Vargo and Lusch, 2008; Fournier and Mick, 1999). This perspective examines the role of the end consumer in the creation of value at both an individual and collective level of analysis, recognising that the end consumer may also be a producer. In contrast, investigation of the role of the firm in value creation is limited to an organisational-level of analysis. This perspective obscures the role of individual managers within the firm in infusing goods, 
services and brands with potential tangible and symbolic value, and how these managers' experiences as consumers are infused within producer roles. In this article, we advance the notion of fluidity between the individual as a producer/manager and also a consumer, and explore the role of 'producers as consumers' within the firm in value creation at an individual level. We use qualitative methods in the organisational context to reveal marketing managers engaging in a complex interplay between ethical consumption ideals and managerial priorities in the work space.

\section{Theoretical Contributions}

In this article, we ask: to what extent do a marketing manager's priorities as a consumer infiltrate workplace decision-making and how does this contamination between domains implicate value creation for the end consumer? In pursuing this line of enquiry through qualitative research, we make two key contributions to marketing theory and practice. We specifically position these contributions within the marketing value creation and co-creation literature streams, directly responding to Vargo et al.'s (2008) and Grönroos and Voima's (2013) call to investigate the processes underpinning value creation and Prahalad and Ramaswarmy's (2004) and Grönroos and Voima's (2013) directive to acknowledge the centrality of the individual to value creation and co-creation.

First, the study details how marketing managers contaminate work place decision making with salient elements of their own consumption derived priorities. This contamination is not unidirectional, however, with the workplace ideals of some informants also infiltrating consumption practices outside of the workplace. The extent that an individual manager's consumer priorities are embedded in potential value creation is contingent on the influence and interplay between their consumer-self and (1) their internalised manager-self, and (2) the external interface with the organisation. Marketing managers are not passive respondents to 
these internal and external influences; rather, they are active agents working to dynamically shape the creation of potential value. In some scenarios, marketing managers manipulate and negotiate the practices and interactions within their organisational context to infiltrate firmled processes of potential value production. In other scenarios, marketing managers actively work to withdraw portions of their consumer-self from the workplace in situations of conflicting work and consumer priorities where boundary re-negotiation is not possible or desired.

Second, we inductively extend these findings to theorise the development of an integrated 'producer as consumer' potential value creation model. This model identifies the mechanisms underpinning the production of potential value by marketing managers at an individual level towards addressing the current lack of theoretical explanation for the value creation processes (Vargo et al. 2008). In particular, ascertaining the extent and conditions under which an individual's own salient consumer-self priorities are embedded as elements of potential value latent in the consumer offering. Embedding salient aspects of potential value into production decisions creates the possibility for consumers, including the marketing manager, to extract these elements as actual value through interactions with offering. Thus, we develop theory to integrate all three of Grönroos and Voima's (2013) value creation scenarios by considering the interplay between the individual's manager-self and consumerself within the workplace: the creation of potential value, the co-production of potential value, and the creation of value (Figure 3). We also show that our model of producer-asconsumer potential value creation - like actual value creation - is both dynamic and situationally derived.

While consumers create actual value-in-use, marketers determine the potential elements of value latent in the offering through their daily workplace decisions (Grönroos and Voima, 2013); such as brand positioning, pricing, and product innovation decisions. 
Thus, consumer experiences of value-in-use are contingent on the decisions of marketing managers. Through our data and theorisation, we show how some marketing managers plumb their consumer-self insight when determining the elements of potential value to be embedded within the market offering. In doing so, these marketing managers internally broaden the integration platform between the producer and the consumer - the joint sphere in Grönroos and Voima's (2013) model - to increase the scope of producer-consumer co-produced potential value in the market offer; bringing their individualised consumer-self into innovation and production decisions to enhance the value creation experience for many consumers. As Keith (informant) suggests: "typically, if I'm thinking it, then a lot of other people are thinking it too". Actively managing this individual level producer-consumer interface and the co-production platform provides an opportunity for the firm to influence the consumer value creation sphere by anticipating salient forms of value-in-use for the consumer. This indirect influence has the potential to yield substantial implications for marketing practice, consumer benefit, and strategic benefit for the firm - as demonstrated by Steve Jobs. Management of these sites of interaction, co-production, and potential value creation are squarely within the remit of the marketing function (Grönroos and Voima 2013, p147). Additionally, the potential for value destruction through marketing manager's decisions illustrates that these decision making processes must be carefully managed (Grönroos and Voima 2013).

\section{INSERT FIGURE 3}

In summary, while current conceptions of value creation and co-creation are shifting to consider a fluid notion of the consumer also as a producer of value (e.g. Ritzer et al., 2012), treatment of the 'firm' remains as a dichotomous entity to the 'consumer' and at an organisation level (e.g. Arvidsson, 2001). The contributions presented in this article begin to re-dress this limited view of the firm in the value creation dynamic. We extend current 
understanding of potential value creation in marketing research (Grönroos and Voima, 2013) by viewing this phenomenon from the perspective of individual managers making decisions within the production organisation. In doing so, we move value creation theory forward by inductively revealing underpinning mechanics of the dynamic potential value creation process. At a macro-level, organisations are formed of individual managers making decisions laden with their own consumer priorities on a daily basis. Individually and collectively, these decisions have significant marketing and market implications.

In addition, we push boundary theory (Nippert-Eng, 1996) into the consumption and marketing arena. In doing so, we extend boundary theory to consider the interplay between manager and consumer-self, and the conditions underpinning the direction of internal and individual-organisational boundary seepage within organisational contexts.

Together, our findings reveal the complexity of business decision making and the role of marketing managers as 'producer-consumers' in the co-production of potential value creation in market offerings.

\section{Managerial Implications}

"We're drowning in a sea of technological crap. Because every product that is released to the market is a result of multiple compromises based on decisions by the product manager, the engineering manager, the marketing manager, the sales manager and everyone else who has skin in the game as they prepare the offering to meet what they think are the target customer's needs. The reason [Steve] Jobs and [Johnny] Ive get it right is because they design sexy products with elegant and simple interfaces - for themselves. Then they count on their hip gaggle of early adopters to see it the same way. Once the snowball starts rolling, it's all momentum from there." (Alain Breillatt, Director of Product Management, Apple)

In addition to contributions to marketing theory, marketing managers may find this research reflexively useful when considering the impacts of integrating their own consumer-self in decision making on value creation. Prahalad and Ramaswamy (2004b) contend that to thrive 
in contemporary markets, businesses must be agile and able to anticipate consumer desires at an individual-level, in real time. To develop this agile and individual-centric ethos, managers must "experience and understand the business as consumers do" ( $p$ 155). We take this a step further to contend that taking the perspective of a producer/consumer - a manager who also recognises their consumer-self - is a credible method to combine with more tradition means in anticipating consumer demands and evaluating production and marketing decisions and options in real time. As suggested by Alain Breillatt, Apple's success was based on Steve Jobs and Johnny Ive designing products "for themselves", illustrating that there is enormous potential for integrating the consumer-self into managerial decisions.

In addition, the potential value creation model advanced in this article may also be a useful tool for production organisations to determine the benefits, and downsides, of encouraging their marketing managers to integrate consumer-self insights into the processes of potential value creation centralised within the firm. As we discovered through this study, the decisions of individual managers can have a significant impact on business operation and performance. For example, we found managers integrating their consumer priorities into decisions about which suppliers to use, which products to range in the company's stores, and which innovation options to invest in. The collective decisions and practices of marketing managers compound at a macro organisational level to create strategic competitive advantage for the firm, or not. Harnessing the consumer's desire to create and co-create value that is personally salient offers a potent source of strategic competitive advantage for the firm (Prahalad and Ramaswamy, 2004b). Our model provides managers and firms with a framework to realise this potential competitive edge by closing the loop between all three value creation scenarios, broadening the interaction platform at an individual level, and instilling salient potential value in the consumer offering. For example, the model may assist 
firms to identify scenarios in which consumer-producer domain permeability should be encouraged to facilitate enhanced consumer experiences of value-in-use.

\section{Future Directions}

We present our inductively derived Producer-as-Consumer Potential Value Creation Model as a first step in understanding the impact of firms in potential value creation at an individual level of analysis. In doing so, we open a field of further research. We acknowledge the limited generalizability of our qualitative study and submit that the integrated model provides a framework to develop and quantitatively test hypotheses, thus presenting a worthy approach to future generalised theory. In addition, we have predominantly focused on the infusion of potential value latent in consumer offerings with a positive value creation orientation for the end consumer. Our findings reveal, however, a dynamic spectrum of value creation - and destruction - possibilities for the individual marketing manager. Future qualitative research investigating the role of individual managers in value co-destruction presents as a rich avenue for future research, as does work assessing the value creation/destruction effects of the producer-as-consumer in marketing decisions. 


\section{References}

Alvesson, M., Ashcraft, K.L., \& Thomas, R. (2008) Identity matters: Reflections on the construction of identity scholarship in organisation studies. Organisation, 15, 5-28.

AMA (2008), “The American Marketing Association releases new definition for marketing”, American Marketing Association.

Anker, T. B., Sparks, L., Moutinho, L., \& Gronroos, C. (2015). Consumer dominant value creation: a theoretical response to the recent call for a consumer dominant logic for marketing. European Journal of Marketing, 49(3/4), 532-560.

Arnould, E., \& Wallendorf, M. (1994) Market-Oriented Ethnography: Interpretation Building and Marketing Strategy Formulation. Journal of Marketing Research, 31, 484-504.

Ashforth, B. E., Kreiner, G.E., \& Fugate, M. (2000) All in a day's work: Boundaries and micro role transitions. Academy of Management. The Academy of Management Review, 25, 472-91.

Arvidsson, A. (2011) Ethics and value in customer co-production. Marketing Theory, 11, 261-78.

Corbin, J., \& Strauss, A. (2008) Basics of Qualitative Research. Thousand Oaks, California: SAGE Publications.

Cova, B., Dalli, D., \& Zwick, D. (2011) Critical perspectives on consumers' role as 'producers': Broadening the debate on value co-creation in marketing processes. Marketing Theory, 11, 231-41.

Echeverri, P., \& Skålén, P. (2011) Co-creation and co-destruction: A practice-theory based study of interactive value formation. Marketing Theory, 11, 351-73.

Edmondson, A.C., \& McManus, S. E. (2007) Methodological Fit in Management Field Research. Academy of Management Review, 32, 1155-79. 
Fournier, S., \& Mick, D. (1999) Rediscovering Satisfaction. Journal of Marketing, 63, 5-23.

Giesler, M. (2012) How Doppelganger Brand Images Influence the Market Creation Process: Longitudinal Insights from the Rise of Botox Cosmetic. Journal of Marketing, 76, 5568.

Grönroos, C. (2011) Value co-creation in service logic: A critical analysis. Marketing Theory, 11, 279-301.

Grönroos, C., \& Ravald, A. (2011). Service as business logic: implications for value creation and marketing. Journal of Service Management, 22(1), 5-22.

Grönroos, C. \& Voima, P. (2013) Critical Service Logic: Making Sense of Value Creation and Co-creation. Journal of the Academy of Marketing Science, 41, 133-50.

Hall, D. T., \& Richter, J. (1989) Balancing Work Life and Home Life: What Can Organisations Do to Help? The Academy of Management Executive, 2, 213-23.

Hammersley, M., \& Atkinson, P. (2008) Ethnography - Principals in Practice (Third ed.). London: Routledge.

Heinonen, K., Strandvik, T., \& Voima, P. (2013). Customer dominant value formation in service. European Business Review, 25(2), 104-123.

Jones, T. M. (1991) Ethical decision making by individuals in organisations: An issuecontingent model. Academy of Management Review, 16, 366-395.

Kjeldgaard, D., Faurholt, F., \& Ger, C. (2006) Grasping the global: multi-sited ethnographic market strategies. In Handbook of Qualitative Research Methods in Marketing, Russell Belk (Ed). Cheltenham, UK: Edward Elgar.

Kreiner, G. E., Hollensbe, E., \& Sheep, M. L. (2009) Balancing Borders and Bridges: Negotiating the Work-Home Interface Via Boundary Work Tactics. The Academy of Management Journal, 52, 704-30. 
Kreiner, G. E., Hollensbe, E. C., \& Sheep, M. L. (2006) On the edge of identity: Boundary dynamics at the interface of individual and organisational identities. Human Relations, 59, 1315-41.

Miles, M., \& Huberman, A. (1994) Qualitative Data Analysis: A Sourcebook of New Methods. Newbury Park, CA: Sage.

Mitchell, R. K., Agle, B. R., \& Wood., D. J. (1997) Toward a theory of stakeholder identification and salience: Defining the principle of who and what really counts. Academy of Management Review, 22, 853-886.

Morris, B. (2008) Steve Jobs Speaks Out. Fortune, February 2008 ed.: Time Inc. URL: http://money.cnn.com/galleries/2008/fortune/0803/gallery.jobsqna.fortune/index.html

Nippert-Eng, C. E. (1996) Home and work: negotiating boundaries through everyday life. Chicago, IL: University of Chicargo Press.

Normann, R., \& Ramirez, R. (1993). Designing interactive strategy. Harvard business review, 71(4), 65-77.

Plé, L., \& Chumpitaz Caceres, R. (2010) Not always co-creation: introducing interactional co-destruction of value in service-dominant logic. Journal of Services Marketing, 24, $430-37$.

Pongsakornrungsilp, S., \& Schroeder, J. E. (2011) Understanding value co-creation in a coconsuming brand community. Marketing Theory, 11, 303-24.

Prahalad, C. K., \& Ramaswamy, V. (2000) Co-opting Customer Competence. Harvard Business Review, 78, 79.

Prahalad, C. K., \& Ramaswamy, V. (2004a) Co-creating unique value with customers. Strategy \& Leadership, 32, 4.

Prahalad, C. K., \& Ramaswamy, V. (2004b) The future of competition : co-creating unique value with customers. Harvard Business School Pub., c2004. 
Ritzer, G., Dean, P., \& Jurgenson, N. (2012) The Coming of Age of the Prosumer. American Behavioral Scientist, 56, 379-98.

Schau, H. J., Muniz, A., \& Arnould, E. J. (2009) How Brand Community Practices Create Value. Journal of Marketing, 73, 30-51.Vargo, S. L., \& Lusch, R. F. (2004) Evolving to a New Dominant Logic for Marketing. Journal of Marketing, 68, 1-17.

Spiggle, S. (1994). Analysis and interpretation of qualitative data in consumer research. Journal of consumer research, 491-503.

Vargo, S. L., \& Lusch, R. F. (2008) Service-dominant logic: continuing the evolution. Journal of the Academy of Marketing Science, 36, 1-10.

Wallendorf, M., \& Belk, R. W. (1989) Assessing Trustworthiness in Naturalistic Consumer Research. In Interpretive Consumer Research, Elizabeth C Hirschman, (Ed.), Provo, UT: Association for Consumer Research.

Zwick, D., Bonsu, S., \& Darmody, A. (2008) Putting Consumers to Work: Co-creation and new marketing govern-mentality. Journal of Consumer Culture, 8, 163 - 96. 


\section{FIGURE 1}

\section{Producer as Consumer - Potential Value Creation Model}

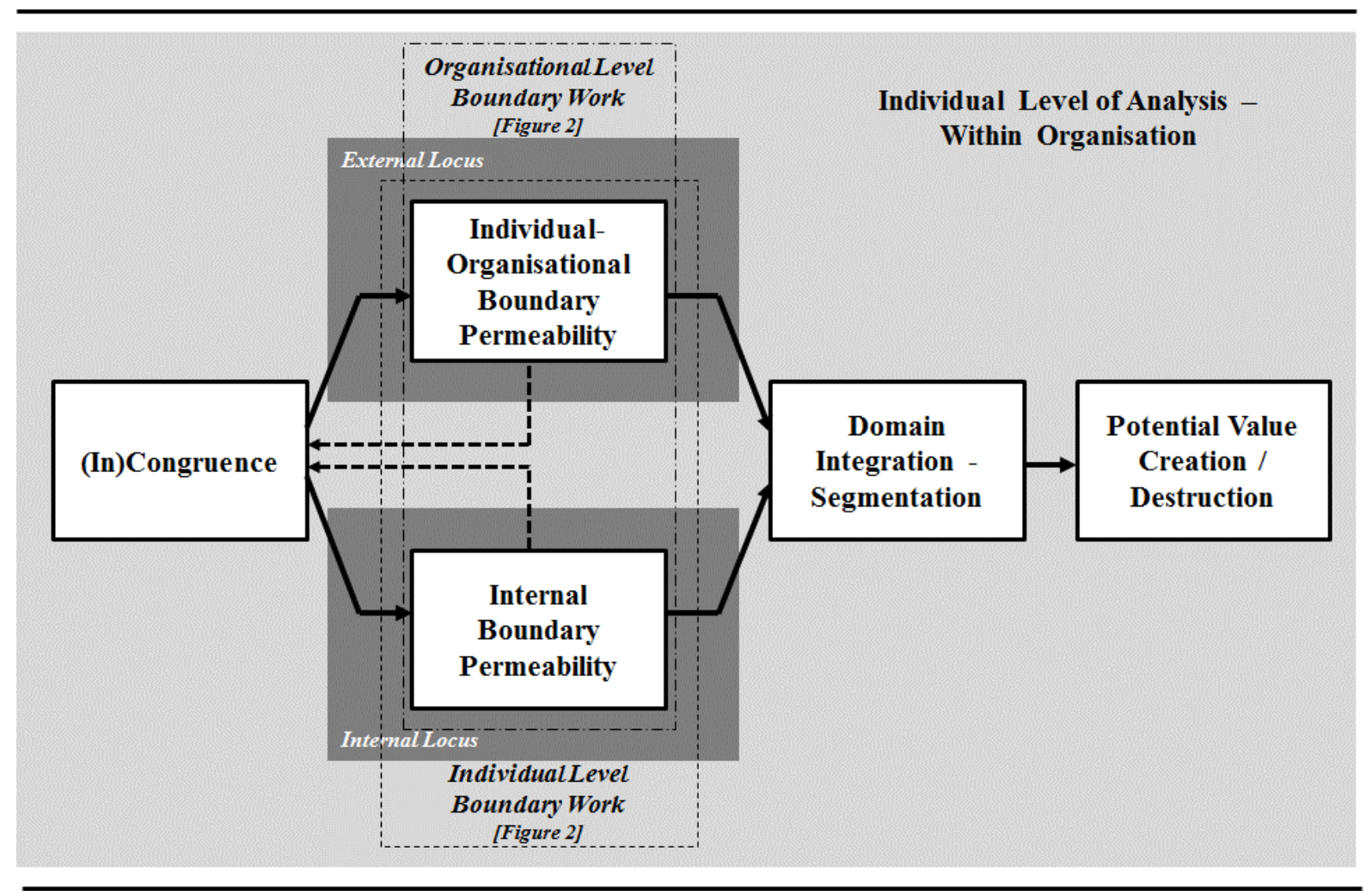




\section{FIGURE 2}

Individual Producer as Consumer - Continuum of Boundary Work Tactics

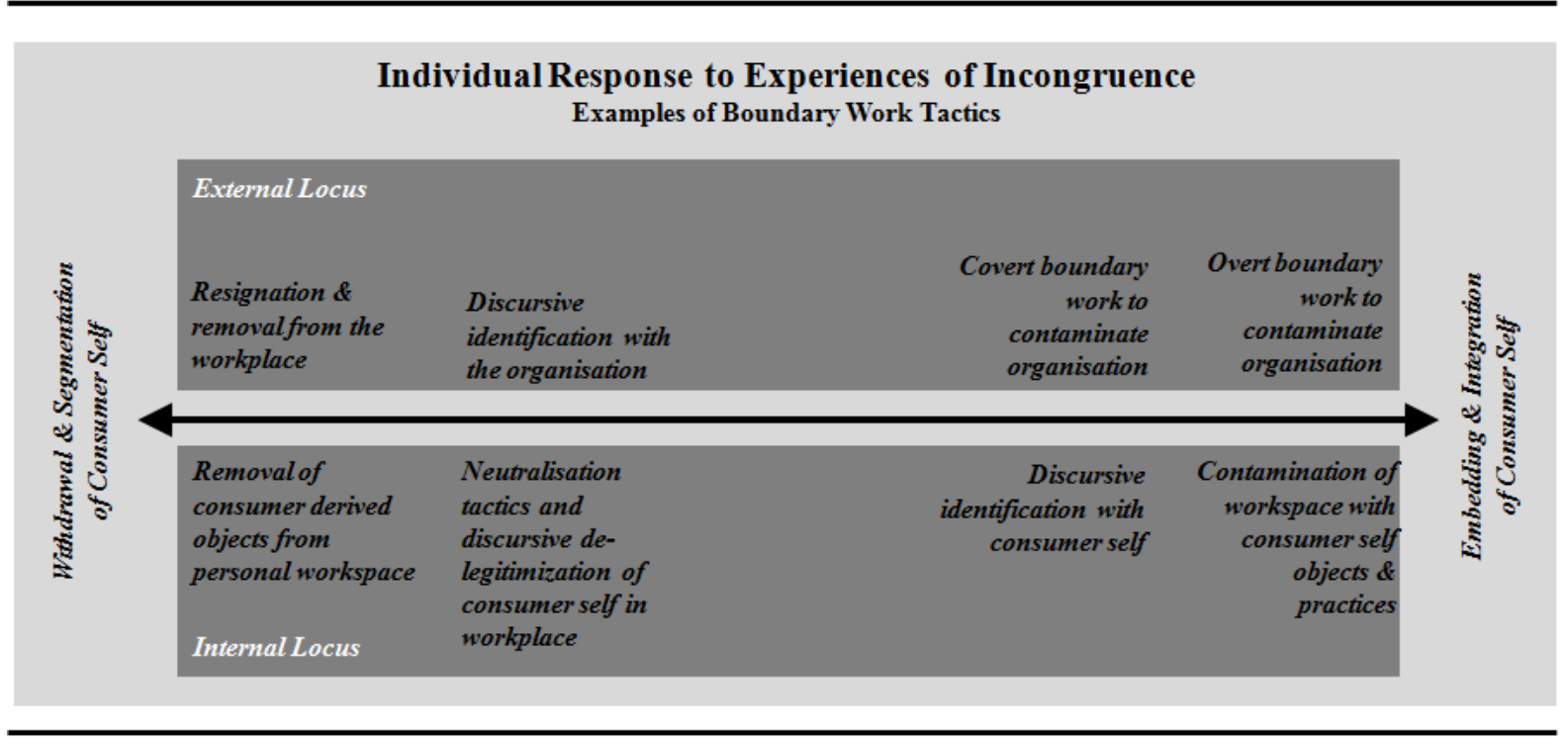




\section{FIGURE 3}

Individual Producer as Consumer - Closing the Value Creation Loop

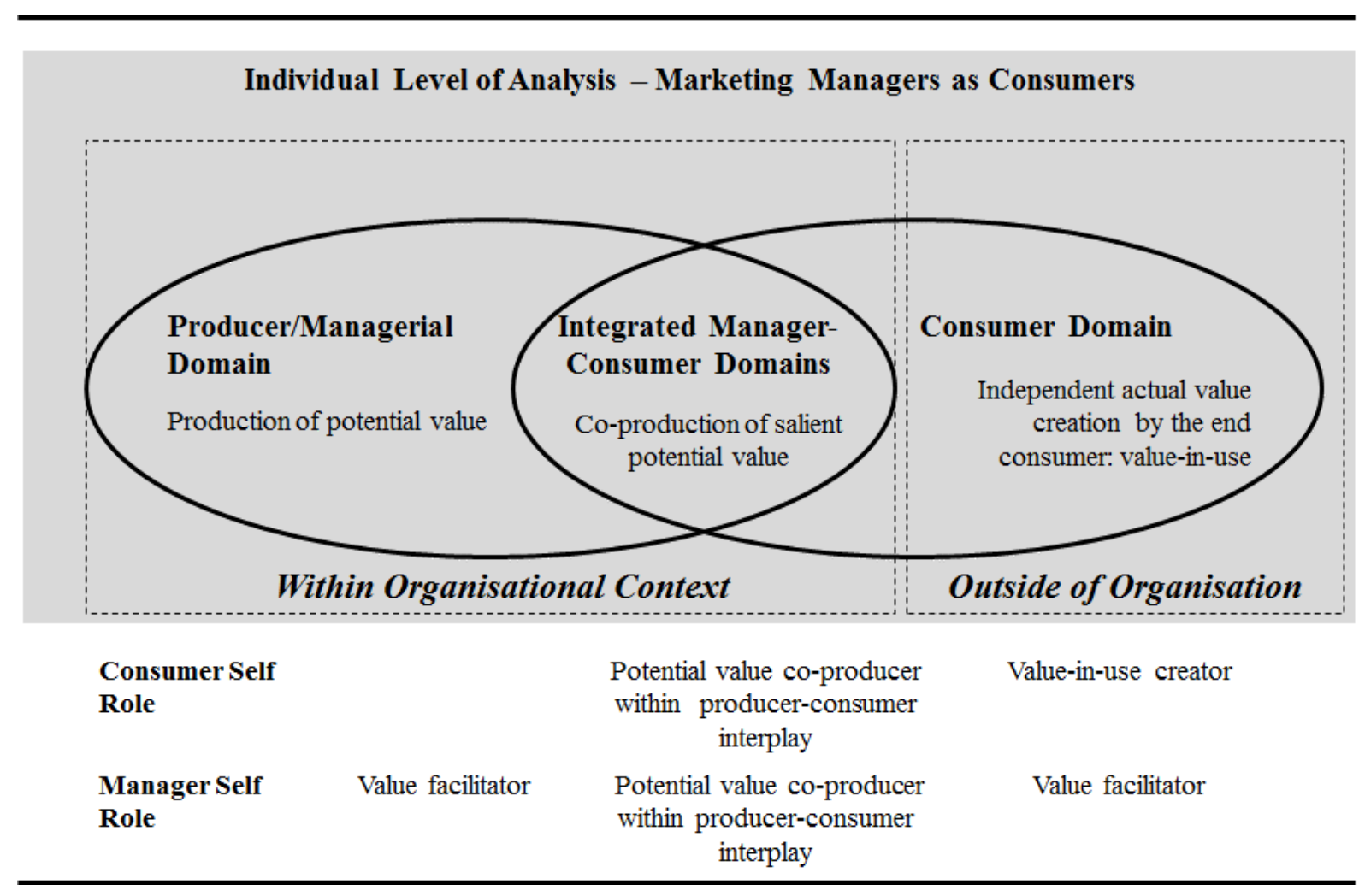




\section{TABLE 1}

\section{Research Participants}

\begin{tabular}{|c|c|c|c|}
\hline Pseudonym & Position/Function & Organization Type & Industry \\
\hline Amber & Sales and Marketing Director & $\begin{array}{l}\text { Manufacturer ('Ethical' focus) } \\
\text { - National distribution } \\
\text { - Market leader or strong competitor }\end{array}$ & $\begin{array}{l}\text { Home and Personal Care } \\
\text { Products }\end{array}$ \\
\hline Anita & $\begin{array}{l}\text { Private Label Development } \\
\text { Manager }\end{array}$ & $\begin{array}{l}\text { Major Retail Chain } \\
\text { - Market Leader }\end{array}$ & Grocery \\
\hline Andy & Head of Marketing & $\begin{array}{l}\text { Manufacturer } \\
\text { - Market Leader } \\
\text { - International Distribution } \\
\end{array}$ & Agricultural/FMCG \\
\hline Bethany & Brand Manager & $\begin{array}{l}\text { Multinational Manufacturer } \\
\text { - Market leader or strong competitor } \\
\text { - International Distribution }\end{array}$ & Personal Care Products \\
\hline Carla & $\begin{array}{l}\text { Marketing \& Product } \\
\text { Manager }\end{array}$ & $\begin{array}{l}\text { Manufacturer and Retailer ('Ethical' focus) } \\
\text { - National Distribution } \\
\text { - Niche / local market }\end{array}$ & Confectionary \\
\hline Diana & Marketing Consultant & $\begin{array}{l}\text { Market Research and Brand Management Consultants } \\
\text { - Multinational } \\
\text { - Market leader in sector }\end{array}$ & $\begin{array}{l}\text { Cross-industry, strong } \\
\text { presence in FMCG }\end{array}$ \\
\hline Gabrielle & Senior Brand Manager & $\begin{array}{l}\text { Multinational Manufacturer } \\
\text { - Market leader or strong competitor }\end{array}$ & FMCG \\
\hline Johan & Supply Chain Manager & $\begin{array}{l}\text { Multinational Manufacturer } \\
\text { - Market leader or strong competitor }\end{array}$ & Alcoholic Beverage \\
\hline Jonathon & Sustainability Director & $\begin{array}{l}\text { Manufacturer } \\
\text { - National Distribution } \\
\text { - Market Leader }\end{array}$ & Automotive \\
\hline Keith & Managing Director/ Founder & $\begin{array}{l}\text { Wholesaler ('Ethical' focus) } \\
\text { - National distribution } \\
\text { - Strong presence in high-end market }\end{array}$ & Paper goods and Stationary \\
\hline Lucas & $\begin{array}{l}\text { Private Label Marketing } \\
\text { Manager }\end{array}$ & $\begin{array}{l}\text { Major Retail Chain } \\
\text { - Market Leader }\end{array}$ & Grocery \\
\hline Mark & $\begin{array}{l}\text { Relationship and } \\
\text { Engagement Manager }\end{array}$ & NGO & FMCG Focus \\
\hline Martin & $\begin{array}{l}\text { Customer Insight / Brand } \\
\text { Management }\end{array}$ & $\begin{array}{l}\text { Manufacturer } \\
\text { - National distribution } \\
\text { - Market Leader }\end{array}$ & Beverages \\
\hline Megan & Marketing Manager & $\begin{array}{l}\text { Manufacturer and Retailer } \\
\text { - Multinational } \\
\text { - Market Leader in Sector }\end{array}$ & Food and Beverages \\
\hline Michael & Category Buyer & $\begin{array}{l}\text { Major Retail Chain } \\
\text { - Market Leader }\end{array}$ & Grocery \\
\hline Michelle & Marketing Manager & $\begin{array}{l}\text { Marketing and Advertising Agency } \\
\text { - Multinational } \\
\text { - Market Leader in Sector }\end{array}$ & Service Industry \\
\hline Nicholas & Head of Marketing & $\begin{array}{l}\text { Manufacturer } \\
\text { - National distribution } \\
\text { - Market Leader }\end{array}$ & Food - Catering \\
\hline Richard & National Account Manager & $\begin{array}{l}\text { Multinational Manufacturer } \\
\text { - Market leader or strong competitor }\end{array}$ & $\begin{array}{l}\text { Foodservice } \\
\text { Catering/Grocery }\end{array}$ \\
\hline Robert & Marketing Manager & $\begin{array}{l}\text { Co-operative Retailer ('Ethical' focus) } \\
\text { - Local co-operative }\end{array}$ & Groceries and Fresh Food \\
\hline Roland & Senior Brand Manager & $\begin{array}{l}\text { Multinational Manufacturer } \\
\text { - Market leader or strong competitor }\end{array}$ & FMCG \\
\hline Sarah & Marketing Manager & $\begin{array}{l}\text { Manufacturer ('Ethical' focus) } \\
\text { - National distribution } \\
\text { - Market leader or strong competitor }\end{array}$ & $\begin{array}{l}\text { Home and Personal Care } \\
\text { Products }\end{array}$ \\
\hline Shelley & Head of Marketing & $\begin{array}{l}\text { Multinational Manufacturer } \\
\text { - Market leader or strong competitor }\end{array}$ & Hardware / DIY \\
\hline Simon & Marketing Manager & $\begin{array}{l}\text { Manufacturer and Retailer ('Ethical' focus) } \\
\text { - National Distribution } \\
\text { - Niche / local market }\end{array}$ & $\begin{array}{l}\text { Fashion Accessories (made } \\
\text { from recycled materials) }\end{array}$ \\
\hline Troy & National Account Manager & $\begin{array}{l}\text { Multinational Manufacturer } \\
\text { - Market leader or strong competitor }\end{array}$ & Agricultural/FMCG \\
\hline William & CEO & $\begin{array}{l}\text { Multinational Manufacturers } \\
\text { - Market leader or strong competitor }\end{array}$ & Various \\
\hline
\end{tabular}




\section{University Library}

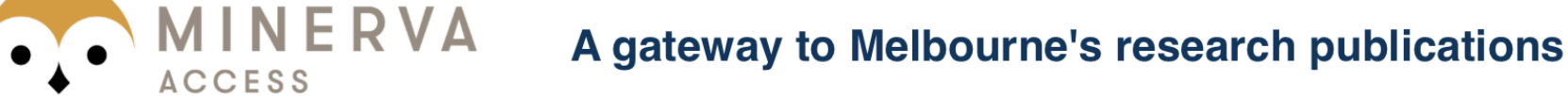

Minerva Access is the Institutional Repository of The University of Melbourne

Author/s:

Carrington, MJ;NEVILLE, B

Title:

Marketers are Consumers Too: Integrating Consumer-Self in Potential Value Creation

Date:

2016

Citation:

Carrington, M. J. \& NEVILLE, B. (2016). Marketers are Consumers Too: Integrating Consumer-Self in Potential Value Creation. European Journal of Marketing, 50 (5/6), pp.863-891. https://doi.org/10.1108/EJM-03-2015-0185.

Persistent Link:

http://hdl.handle.net/11343/247861 